\title{
Tuning the performance of vanadium redox flow batteries by modifying the structural defects of the carbon felt electrode
}

\author{
Ditty Dixon ${ }^{* 1}$, Deepu Joseph Babu ${ }^{2}$, Aiswarya Bhaskar ${ }^{1}$, Hans-Michael Bruns ${ }^{3}$, \\ Joerg J. Schneider ${ }^{2}$, Frieder Scheiba ${ }^{3}$ and Helmut Ehrenberg ${ }^{3}$
}

\section{Full Research Paper}

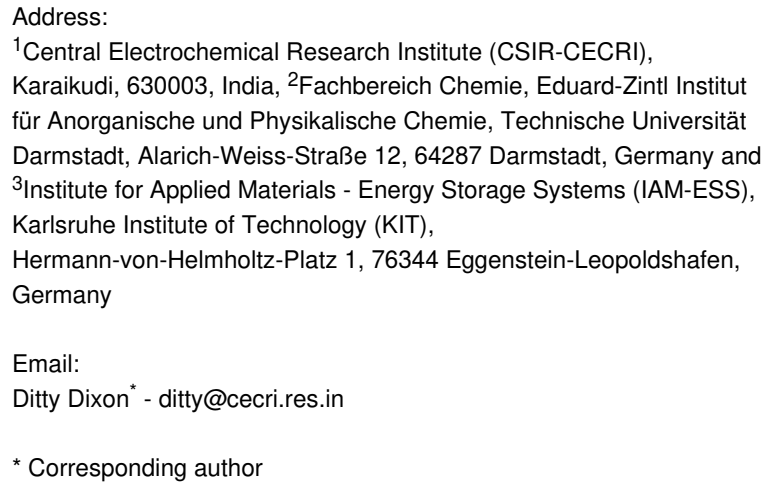

${ }^{1}$ Central Electrochemical Research Institute (CSIR-CECRI), Karaikudi, 630003, India, ${ }^{2}$ Fachbereich Chemie, Eduard-Zintl Institut für Anorganische und Physikalische Chemie, Technische Universität Darmstadt, Alarich-Weiss-Straße 12, 64287 Darmstadt, Germany and ${ }^{3}$ Institute for Applied Materials - Energy Storage Systems (IAM-ESS), Karlsruhe Institute of Technology (KIT), Hermann-von-Helmholtz-Platz 1, 76344 Eggenstein-Leopoldshafen, Germany

Email:

Ditty Dixon* - ditty@cecri.res.in

* Corresponding author

Keywords:

carbon felt; defects; nitrogen plasma; vanadium redox flow battery (VRFB)
Beilstein J. Nanotechnol. 2019, 10, 1698-1706. doi:10.3762/bjnano.10.165

Received: 26 April 2019

Accepted: 19 July 2019

Published: 13 August 2019

This article is part of the thematic issue "Carbon-based nanomaterials for energy applications".

Guest Editor: B. Etzold

(C) 2019 Dixon et al.; licensee Beilstein-Institut. License and terms: see end of document.

\begin{abstract}
Polyacrylonitrile (PAN)-based carbon felt was subjected to $\mathrm{N}_{2}$-plasma treatment to increase the heteroatom defects and reactive edge sites as a method to increase the performance in vanadium redox flow batteries (VRFBs). N-doping in the felt was mainly in the form of pyrrolic and pyridinic nitrogen. Even though the amount of oxygen functional groups on the $\mathrm{N}_{2}$-plasma-treated sample was very low, the felt showed enhanced electrochemical performance for both $\mathrm{V}^{3+} / \mathrm{V}^{2+}$ as well as $\mathrm{V}^{5+} / \mathrm{V}^{4+}$ redox reactions. The result is highly significant as the pristine electrode with the same amount of oxygen functional groups showed significantly less activity for the $\mathrm{V}^{3+} / \mathrm{V}^{2+}$ redox reaction. Overall, the single-flow cell experiments with $\mathrm{N}_{2}$-plasma-treated felt showed superior performance compared to the pristine sample. Therefore, the enhanced performance observed for the $\mathrm{N}_{2}$-plasma-treated sample should be attributed to the increase in defects and edge sites. Thus, from the present study, it can be concluded that an alternate way to increase the performance of the VRFBs is to introduce specific defects such as N-doping/substitution or to increase the edge sites. In other words, defects induced in the carbon felt such as heteroatom doping are as beneficial as the presence of oxygen functional groups for the improved performance of VRFBs. Therefore, for an optimum performance of VRFBs, defects such as N-substitution as well as oxygen functionality should be tuned.
\end{abstract}




\section{Introduction}

In every part of the world, the contribution of electrical energy harvested from a renewable source, such as wind, photovoltaics, etc., to the electrical grid system is increasing. In contrast to electric energy production from fossil or nuclear fuels, the generation of energy from renewable sources is intermittent by nature. The intermittent nature of such energy production can lead to the destabilization of the grid. This issue demands the development of durable and efficient electrical energy storage systems which can store the excess electrical energy from renewable energy sources during peak production and supply the stored energy to the grid during a depletion in the production. In this context, the all-vanadium redox flow battery (VRFB) is one of the most promising and flexible stationary electrical energy storage systems. Unlike $\mathrm{Pb}$ acid, Li-ion batteries or even flow batteries like zinc/bromine, the electrical energy in VRFBs is completely stored by the electrolyte in an external tank. Thus, in VRFB systems, the power and energy can be decoupled, that is, to store more energy, only the tank size needs to be increased. Moreover, since the system uses only a single redox species, element cross-contamination issues, which are common in other redox flow batteries such as $\mathrm{Cr} / \mathrm{Fe}$, are obviously nonexistent [1]. Nevertheless, the system suffers from irreversible capacity fade due to parasitic reactions such as air oxidation of $\mathrm{V}^{2+}$ species and hydrogen evolution reaction (HER) at the negative electrode [2-4]. The air oxidation of $\mathrm{V}^{2+}$ species can be completely prevented by keeping the negative tank under inert gas atmosphere. However, the HER at the negative electrode is almost unavoidable as the redox potential of $\mathrm{V}^{3+} / \mathrm{V}^{2+}(-0.26 \mathrm{~V}$ vs normal hydrogen electrode (NHE)) reaction is very close to HER ( $0 \mathrm{~V}$ vs NHE). To minimize the HER, the negative electrode surface structure should be tuned in such a way that it tends to preferably bind $\mathrm{V}^{3+} / \mathrm{V}^{2+}$ ions over $\mathrm{H}^{+}$ions. Creating oxygen functional groups on the surface of the anode is one way to achieve this [5,6]. Langner et al. have shown that on a functionalized electrode, in the presence of $\mathrm{V}^{3+}$, the HER is suppressed as the $\mathrm{V}^{3+}$ ions get preferentially bonded to the oxygen functional groups [6]. Furthermore, they proposed that it is essential to have at least $5 \%$ oxygen functionality on the surface of the carbon felt for the unhindered reduction of $\mathrm{V}^{3+}$ ions. In fact, carbon felt with a surface coverage as high as $23 \%$ oxygen functionality showed relatively enhanced VRFB performance [7]. Nevertheless, the above-mentioned electrode with a higher amount of oxygen functional groups, when used in a three-electrode configuration, showed poor electrochemical performance for the positive $\left(\mathrm{V}^{5+} / \mathrm{V}^{4+}\right)$ redox reaction. Taking into account that the negative redox reaction is the limiting reaction in VRFB, the overall enhancement in the full cell performance was purely attributed to enhancement in the $\mathrm{V}^{3+} / \mathrm{V}^{2+}$ redox kinetics due to the presence of functional groups [8]. Thus, it is extremely important to optimize and maintain the amount of functional groups on the surface of the carbon felt especially when used as a negative electrode in VRFB. However, it has been found that due to electrochemical as well as chemical ageing, both electrode surfaces tend to oxidize with the additional formation of oxygen functional groups $[9,10]$. Excess oxidation of the carbon felt can also introduce nonselective functional groups such as $-\mathrm{C}-\mathrm{O}$ and $-\mathrm{C}=\mathrm{O}$ and reduces the $\mathrm{sp}^{2}$ carbon content or the graphite content of the felt. The formation of nonselective functional groups can impede the redox reaction. For example, Estevez et al. showed that the presence of $-\mathrm{O}-\mathrm{C}=\mathrm{O}$ groups increases the performance of the VRFB whereas the presence of $-\mathrm{C}-\mathrm{O}$ and $-\mathrm{C}=\mathrm{O}$ degrades it [11]. In the long run, reduction in the graphite or $\mathrm{sp}^{2}$ carbon content of the felt reduces the electrical conductivity, leading to performance loss. Furthermore, it has been proposed by Schweiss et al. that an increase in the amorphous content in the felt can increase the hydrogen evolution reaction [12]. In one way or the other, functionalization with heteroatoms will always reduce the graphitic nature as functionalization proceeds by breaking of the $\mathrm{C}_{6}$ rings, and in many cases, with the formation of a $\mathrm{sp}^{3}$ hybridized carbon atoms (out of plane with the graphene layer). Moreover, most of these functional groups will be predominantly formed at graphite edge sites which are much more active than a basal carbon [13]. Therefore, to obtain reasonable VRFB performance, the carbon edge sites of the carbon felt electrode should be preserved or the functional group formed on this site by chemical or electrochemical ageing should promote the redox reaction. Another possible way to create a reaction site or catalytic center in graphite is by doping it with heteroatoms such as $\mathrm{B}, \mathrm{N}$, or $\mathrm{P}$. The heteroatom perturbs the electronic structure of the graphite layer subjected to doping, leading to enhanced polarization [14]. N-doped carbon-based electrodes have been successfully tested in VRFBs. For example, Wang et al. developed carbon felt deposited with N-doped carbon nanotubes which showed enhanced VRFB performance [15]. He et al. produced $\mathrm{N}$-doped carbon felt by heating the commercial felt at 600 and $900{ }^{\circ} \mathrm{C}$ in the presence of $\mathrm{NH}_{3}$ gas. This felt showed enhanced VRFB performance, owing to the increase in electrical conductivity as well as active sites [16]. In this work, a carbon felt electrode with minimum oxygen functional groups and a larger amount of defects in the form of $\mathrm{N}$-doping and edge sites was prepared by employing the $\mathrm{N}_{2}$ plasma technique. The $\mathrm{N}_{2}$-plasma-treated sample showed enhanced electrochemical performance in a VRFB compared to the untreated sample with fewer defects. The commercial carbon felts (GFD-type) used as electrode materials in the present study are made out of a polyacrylonitrile (PAN) precursor. In contrast to the commonly employed thermal activation process, the plasma treatment process is quick, and subsequent physical or chemical changes incurred will be uniform across the felt. 
Apart from that, it is observed that the surface area of the material is not affected by the plasma treatment process.

\section{Results and Discussion}

In this work, the $\mathrm{N}_{2}$ plasma treatment process is applied to PAN-based felts to increase the amount of defects. The normalized spectra obtained for the Raman measurements are shown in Figure 1. In order to investigate the degree of graphitization and defects formed during the plasma treatment process, the intensity of the G- and D-band centered at $1590 \mathrm{~cm}^{-1}$ and $1356 \mathrm{~cm}^{-1}$ are compared. The G-band in graphitic material arises from the in-plane vibration of $\mathrm{sp}^{2}$ carbon atoms. Whereas the D-band arises from out-of-plane vibrations from carbon associated with defects. Therefore, the ratio of the intensity of the D- and G-bands $\left(I_{\mathrm{D}} / I_{\mathrm{G}}\right)$ gives direct information about the extent of defects in a graphite material $[17,18]$. From the Raman spectral analysis, it was found that the pristine sample had a lower $I_{\mathrm{D}} / I_{\mathrm{G}}$ ratio of 1.2 compared to the $\mathrm{N}_{2}$-plasma-treated sample of 1.7. This indicates that the $\mathrm{N}_{2}$ plasma treatment process served to increase the defects in the carbon felt. Moreover, the D-band of the plasma-treated sample was shifted to a higher frequency, indicating an increase in the defect density. Mostly, this increase in defects can be correlated to heteroatom substitution/doping (N-doping) and the simultaneous creation of new edge sites [17]. At $2690 \mathrm{~cm}^{-1}$ a symmetric second order D-band (2D) is visible for both samples. Careful analysis reveals that the $2 \mathrm{D}$ peak intensity is lower for the plasma-treated sample, indicating possible doping [17].

In order to investigate the $\mathrm{N}$-doping in a plasma-treated felt, X-ray photoelectron spectroscopy (XPS) analysis of the samples was carried out. The $\mathrm{N}_{2}$-plasma-treated sample was characterized by a N 1s peak with maxima around $399 \mathrm{eV}$. The N 1s peak could be deconvoluted into pyridinic and pyrrolic $\mathrm{N}$ contributions, with maxima at 398.3 and $399.8 \mathrm{eV}$, respectively. The XPS results, as well as the quantification of various groups on the surface of the felt are shown in Figure 2. Thus, from these results, it can be concluded that $\mathrm{N}_{2}$ plasma treatment can be applied to induce $\mathrm{N}$-doping defects. Both pyrrolic as well as pyridinic $\mathrm{N}$ observed in the XPS spectra are incorporated into the graphene layer $[19,20]$. The doping of $\mathrm{N}$ as observed here differs from the functionalization by the fact that during the doping process, the $\mathrm{N}$ atom is directly bonded with other carbon atoms inside the graphene framework, whereas during the functionalization process, the nitrogen groups are bonded on one of the edge sites of the carbon atoms. Since XPS shows only the presence of pyrrolic and pyridinic contributions, any $\mathrm{N}$-functionalization can be ruled out [20,21]. In contrast to oxygen, nitrogen is less reactive, and its atomic size is close to carbon. Therefore, with $\mathrm{N}_{2}$ plasma treatment, doping prevails over functionalization. The elementary composition from the XPS analysis revealed the presence of approximately $2 \%$ of nitrogen on the surface of the felt, which translates into a substantial amount of $\mathrm{N}$ doping, given that a $\mathrm{N}$-doping level as low as 1 atom \% can have a significant effect on the electronic structure of carbon materials [22].

Additionally, from the XPS analysis, approximately $2 \%$ and $3 \%$ of oxygen functional groups $(\mathrm{C}=\mathrm{O}$ and $\mathrm{C}-\mathrm{O})$ was found to be present on both pristine as well as plasma-treated samples, respectively. Furthermore, it can also be seen from the XPS results that, compared to the pristine sample, the $\mathrm{N}_{2}$-plasmatreated sample has the highest graphitic content on the surface. This result contradicts the Raman spectroscopy result where the plasma-treated sample in fact showed more defects. It must be emphasized that in the present work no peak fitting was carried out on the $\mathrm{C} 1 \mathrm{~s}$ peak to quantify the defects. It may be stressed that the graphite content obtained from XPS also has a contribu-

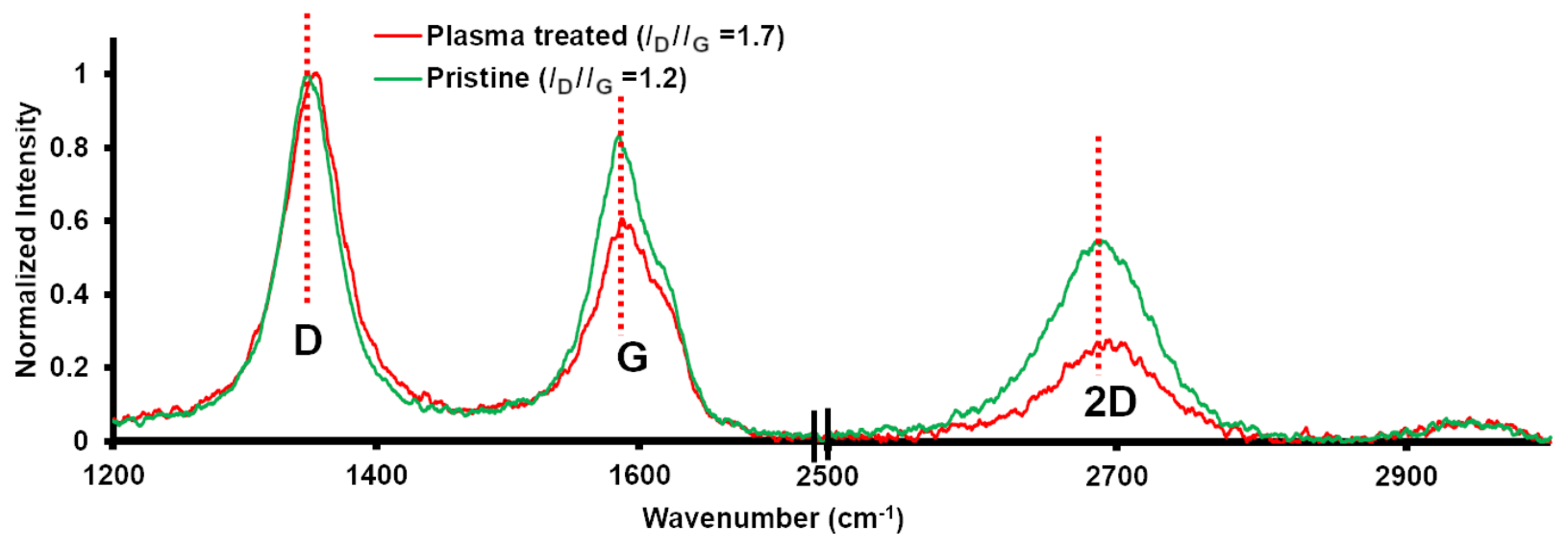

Figure 1: Raman spectra obtained for pristine as well as $\mathrm{N}_{2}$-plasma-treated sample. 

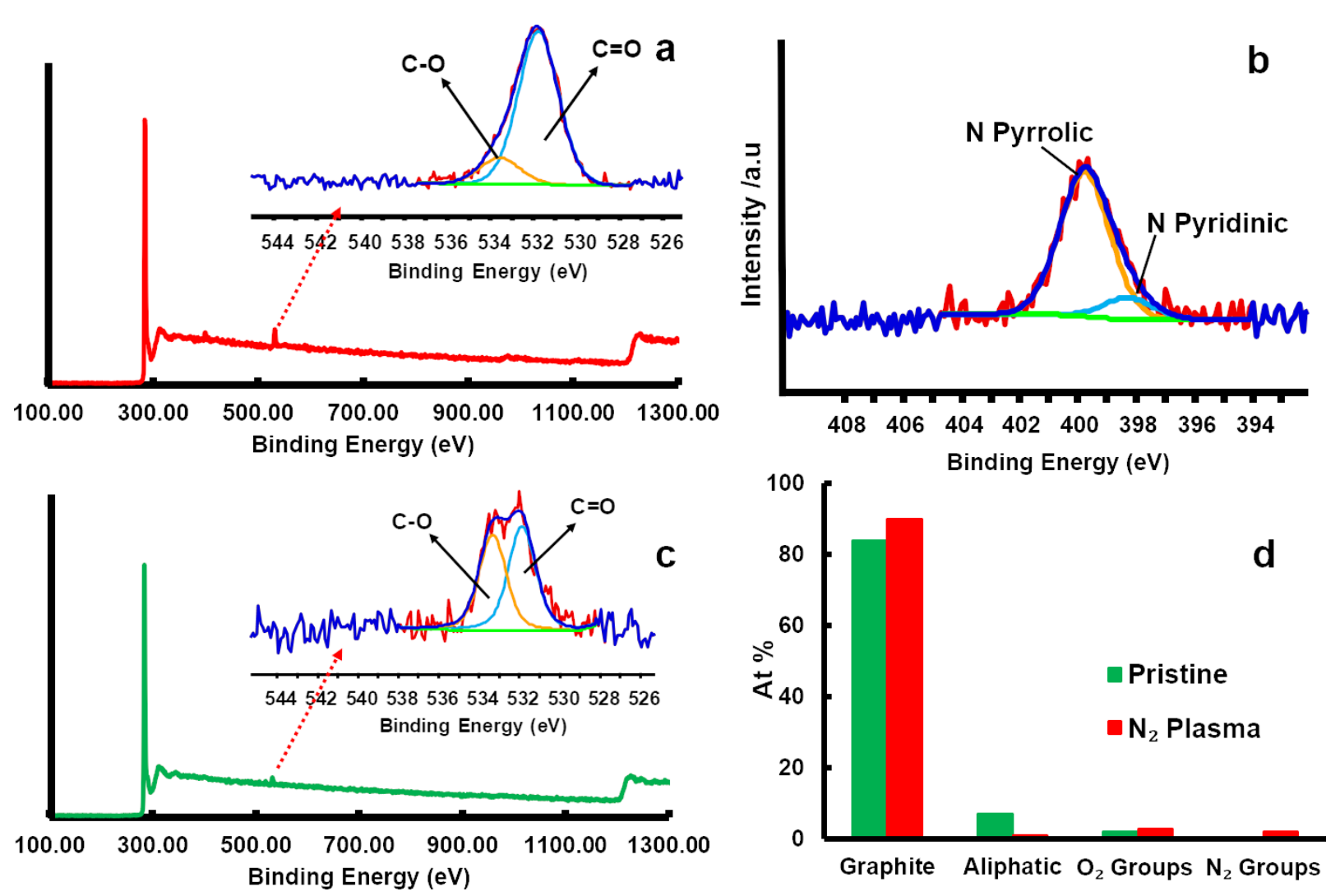

Figure 2: XPS results obtained for pristine and $\mathrm{N}_{2}$-plasma-treated samples. a) Survey scan for the $\mathrm{N}_{2}$-plasma-treated sample and inset showing the $\mathrm{O}$ 1s peak fitting results, b) $\mathrm{N} 1 \mathrm{~s}$ peak fitting for the $\mathrm{N}_{2}$-plasma-treated sample, c) survey scan for the pristine sample and inset showing the $\mathrm{O}$ 1s peak fitting results, and d) composition of the various groups obtained after peak fitting.

tion from the defects. The increase in the graphitic amount could be correlated to the corresponding decrease in the amount of aliphatic carbon. The source of this aliphatic carbon is either from the graphitization process of the PAN fibers or simply the atmospheric ageing of the felt. It is already known from the literature that graphitization or atmospheric ageing can leave some aliphatic or polyaromatic tar-like residues on the surface of the felt $[6,23]$. Thus, it can be concluded that apart from inducing $\mathrm{N}$-doping, the $\mathrm{N}_{2}$ plasma treatment also increased the apparent graphite amount on the surface by removing the aliphatic groups $(\mathrm{C}-\mathrm{H}$ and $\mathrm{C}-\mathrm{C})$ from the surface of the fibers. The schematic representation of $\mathrm{N}$-doping induced by the $\mathrm{N}_{2}$ plasma treatment in a graphite lattice is shown in Figure 3.

From the scanning electron microscopy (SEM) analysis, it can be seen that the surface morphology of the fibers of both samples looked identical and thus any kind of surface roughening leading to an increase of the surface area can be ignored. This is further supported by our previous study were the BET measurements did not show any increase in surface area for oxygenplasma-treated samples [7]. The SEM images of the pristine as well as the $\mathrm{N}_{2}$-plasma-treated samples are shown in Figure 4.
In order to evaluate the electrochemical performance of the $\mathrm{N}_{2}$-plasma-treated sample, cyclic voltammetry (CV) measurements were carried out. In contrast to the pristine sample, a prominent $\mathrm{V}^{3+} / \mathrm{V}^{2+}$ redox peak is observed for the $\mathrm{N}_{2}$-plasmatreated sample. The $\mathrm{CV}$ of the pristine sample is mainly characterized by a hydrogen evolution peak. The CV curves for both negative and positive redox reactions are shown in Figure 5 .

Given that the pristine and $\mathrm{N}_{2}$-plasma-treated samples have almost the same amount of oxygen functional groups, the enhanced activity shown by $\mathrm{N}_{2}$-plasma-treated samples towards the $\mathrm{V}^{3+} / \mathrm{V}^{2+}$ redox reaction should be attributed to the specific defects such as $\mathrm{N}$-doping and the increase of the edge sites. More recently, $\mathrm{Xu}$ et al. showed, using first-principle calculations, that $\mathrm{N}$-doping (especially the pyridinic and pyrrolic forms) enhances the water adsorption or hydrophilicity of the graphite electrode [24]. Thus, it may be concluded that the pyridinic and pyrrolic nitrogen formed during the $\mathrm{N}_{2}$-plasma process enhanced the wettability of the felt, which in turn facilitates the adsorption of the $\mathrm{V}^{2+} / \mathrm{V}^{3+}$ ions. Apart from defects in the form of $\mathrm{N}$-doping, a higher amount of edge sites formed 


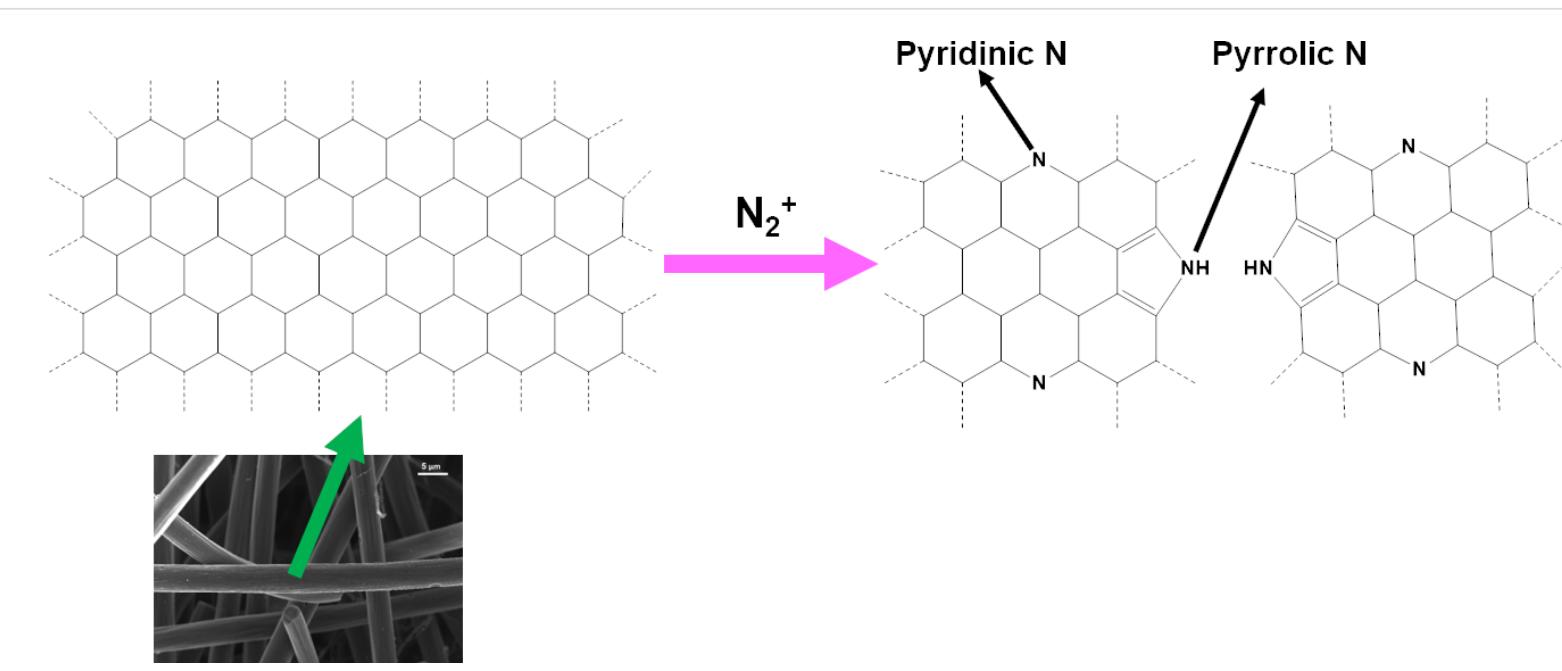

Figure 3: Schematic representation of $\mathrm{N}$-doping induced by $\mathrm{N}_{2}$ plasma treatment in a graphite lattice.

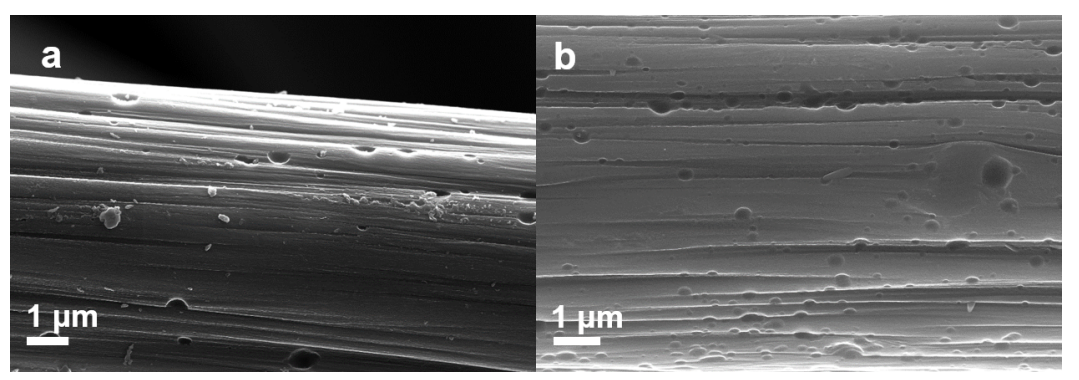

Figure 4: SEM images of a) pristine and b) $\mathrm{N}_{2}$-plasma-treated samples.

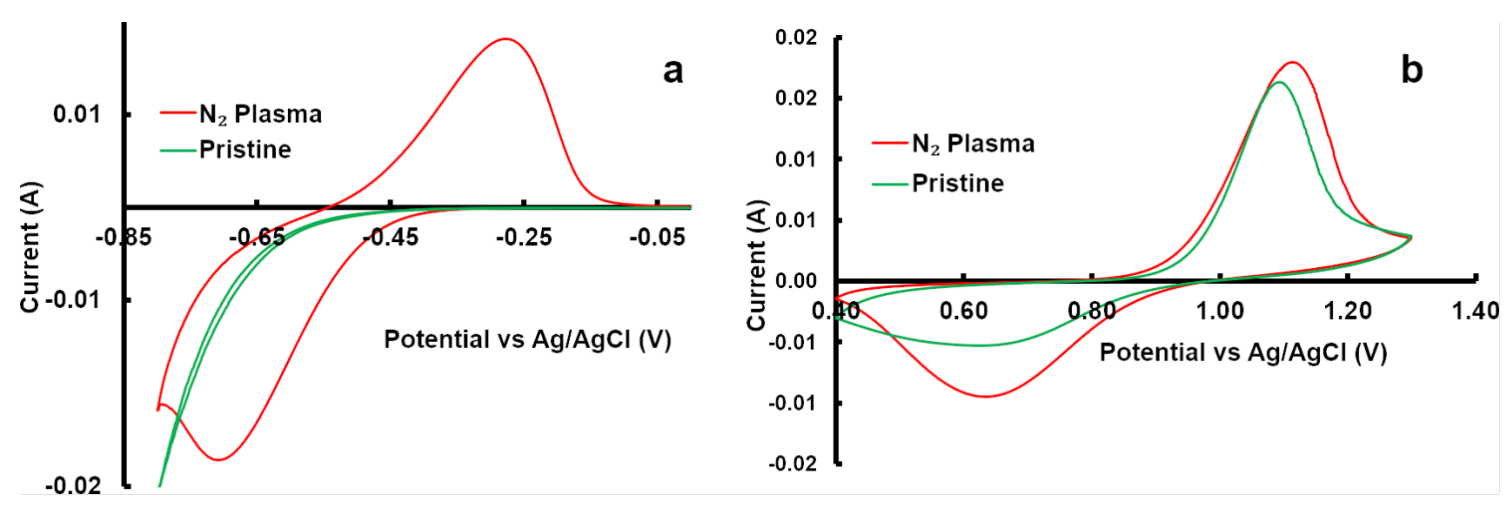

Figure 5: CV curves obtained for the pristine and the $\mathrm{N}_{2}$-plasma-treated sample: a) negative redox reaction, b) positive redox reaction.

during the $\mathrm{N}_{2}$-plasma process also influences the $\mathrm{V}^{3+} / \mathrm{V}^{2+}$ redox reaction. This is because the half-cell reaction is known to depend greatly on the carbon edge sites [25]. Another reason for the enhanced activity of the $\mathrm{N}_{2}$-plasma-treated samples towards the $\mathrm{V}^{3+} / \mathrm{V}^{2+}$ reaction is that the aliphatic carbonaceous materials on the surface of the felts are removed during the $\mathrm{N}_{2}$-plasma process. As a result of this process, more electrochemically active sites (edge sites) are available for the $\mathrm{V}^{3+} / \mathrm{V}^{2+}$ redox reaction. As far as the $\mathrm{V}^{5+} / \mathrm{V}^{4+}$ redox reaction (i.e., the positive redox reaction) is concerned, both pristine, as well as $\mathrm{N}_{2}$-plasma-treated carbon felts showed electrochemical activity. Compared to pristine carbon felt the $\mathrm{N}_{2}$-plasma-treated sample 
showed an earlier onset potential for the $\mathrm{V}^{5+} / \mathrm{V}^{4+}$ redox reaction. Thermodynamically, the $\mathrm{V}^{4+}$ to $\mathrm{V}^{5+}$ redox reaction takes place at $1.0 \mathrm{~V}$ vs a normal hydrogen electrode (NHE). Taking into account that carbon oxidation is feasible at potentials as low as $207 \mathrm{mV}$ vs NHE [26], the higher potential of positive electrode of the VRFB can accelerate the carbon oxidation. During the carbon oxidation process, oxygen functional groups can be formed as an intermediate on the carbon electrode $[27,28]$. Therefore, oxygen functional groups can be formed on the surface of the felt, and especially on the positive electrode as it experiences a relatively higher potential. In fact, Derr et al have observed an increase in the amount of functional groups on the surface of both negative and positive carbon felt electrodes after prolonged cycling [9]. Given that a higher potential is favorable for carbon oxidation, it can be concluded that the presence of functional groups on the carbon felt is not a prerequisite for the onset of the $\mathrm{V}^{5+} / \mathrm{V}^{4+}$ redox reaction. $\mathrm{CV}$ studies were further supported by full cell studies, where the electrochemical performance of the $\mathrm{N}_{2}$-plasma-treated sample was superior to the pristine sample. The cell with the $\mathrm{N}_{2}$-plasmatreated sample showed a higher energy efficiency and delivered higher capacities at all investigated current densities. The single-cell measurement results are shown in Figure 6. With the pristine sample at higher current densities $\left(\geq 64 \mathrm{~mA} \mathrm{~cm}^{-2}\right)$, the cell ran into HER. Since the negative electrode reaction is the performance-limiting reaction, the superior performance observed for the single-cell measurement could be attributed to the enhancement in the $\mathrm{V}^{2+} / \mathrm{V}^{3+}$ redox reaction. However, it could also be seen that the performance of the pristine and the $\mathrm{N}_{2}$-plasma-treated sample improves with further cycling, and during the final cycle (13-16) the cells delivered higher capacities compared to the initial cycles (1-4).

This increase in performance can be attributed to oxygen functional groups (both hydroxyl and carboxyl) formed on the surface of the felt due to the chemical and the electrochemical ageing process as elucidated by Derr et al. [9]. Nevertheless, a capacity fade was observed on the $\mathrm{N}_{2}$-plasma-treated sample after long-term cycling at a current density of $80 \mathrm{~mA} \mathrm{~cm}^{-2}$ (see Figure 7). Capacity fade can be partially attributed to the HER taking place at the negative electrode due to the very low amount of oxygen functional groups. Moreover, the Nafion 117 membrane used for higher current density cycling leads to an electrolyte imbalance. A detailed investigation is still required to understand the overall mechanism of the capacity fade.

In a previous study [7], a similar extent of capacity fade was observed for heat-treated GFD (graphite-based) carbon felt samples with a higher amount of oxygen functional groups and a larger surface area than in this study. Nevertheless, the energy efficiency of the cell with the $\mathrm{N}_{2}$-plasma-treated electrode is higher than that with the heat-treated electrode. Therefore, for achieving the optimum VRFB performance, the electrodes, especially the anode, must be tuned for defects such as $\mathrm{N}$-sub-
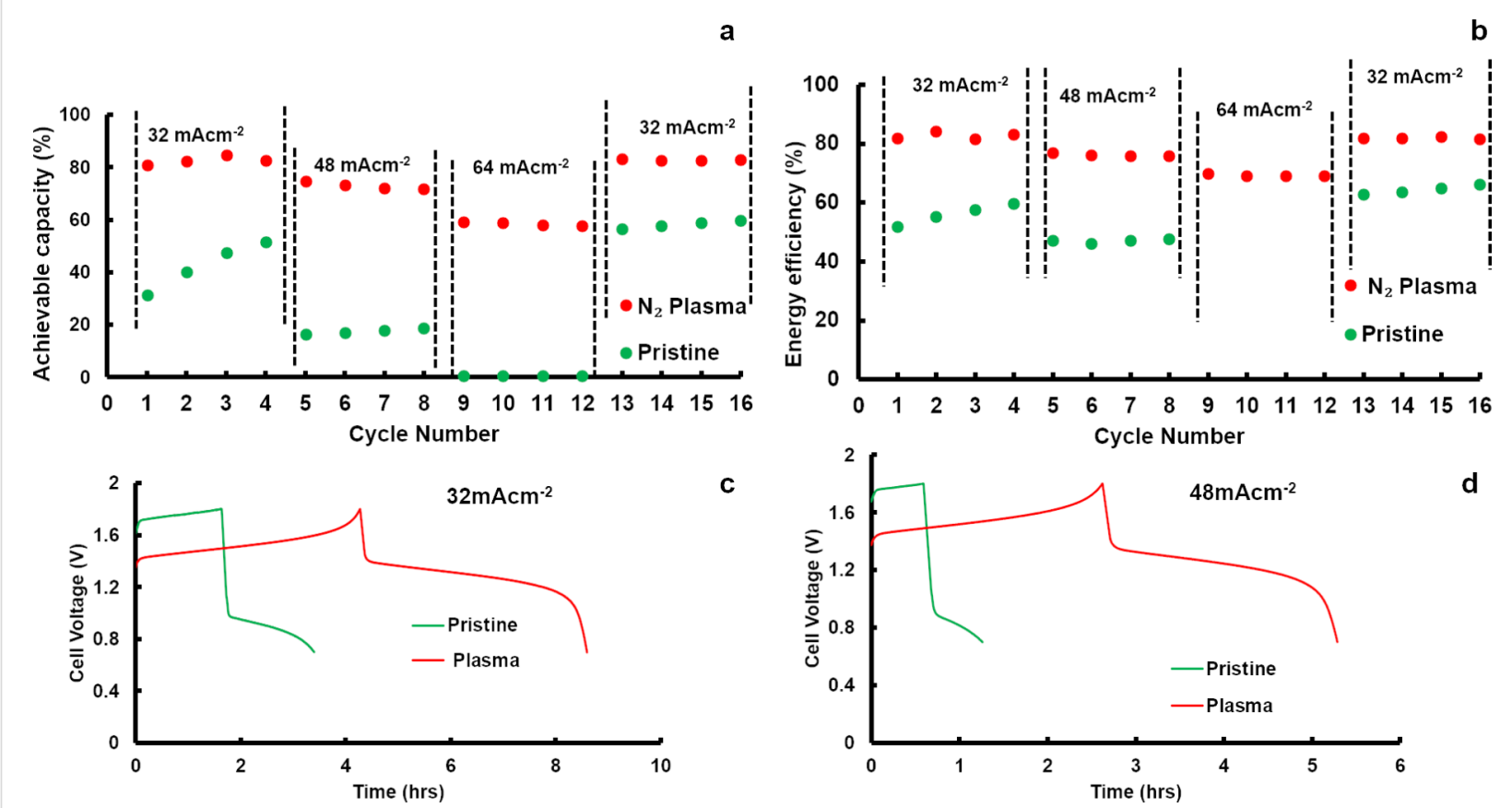

C

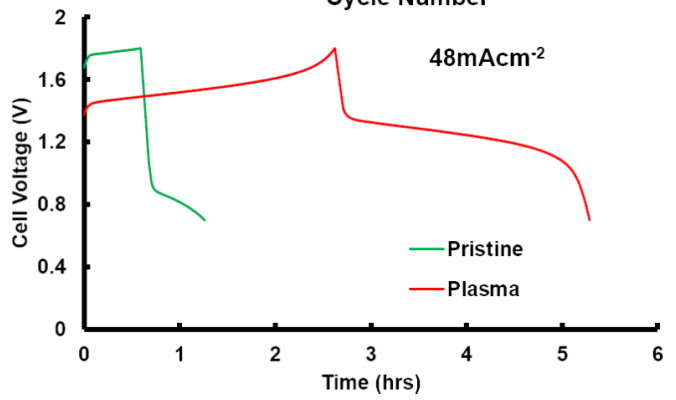

Figure 6: Single-cell measurement results with pristine (green) and $\mathrm{N}_{2}$-plasma-treated samples (red). a) Maximum discharge capacity obtained during cycling, b) energy efficiency achieved during cycling, c) charge-discharge curve obtained for cycling at $32 \mathrm{~mA} \mathrm{~cm}^{-2}$, d) charge-discharge curve obtained for cycling at $48 \mathrm{~mA} \mathrm{~cm}^{-2}$. 


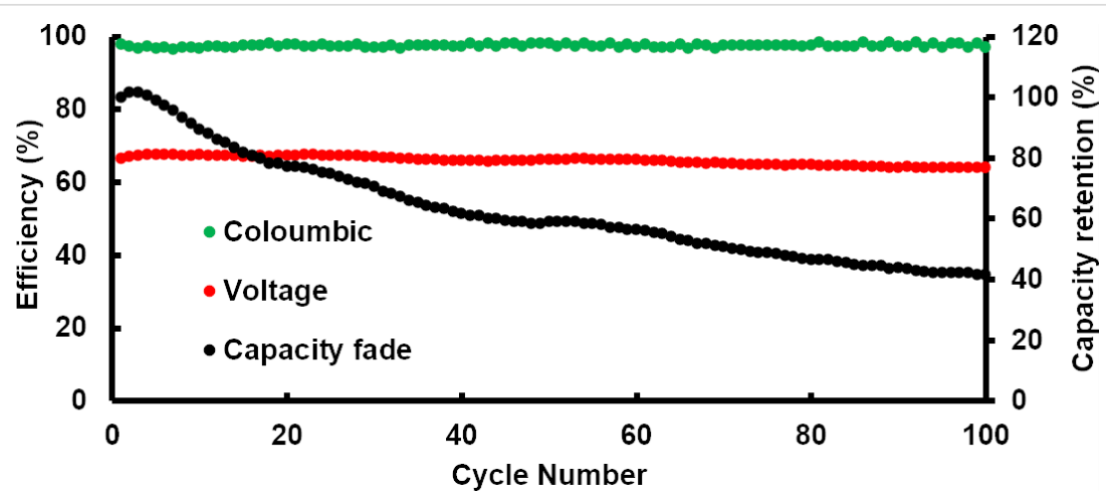

Figure 7: Evolution of efficiency and capacity retention during long-term cycling with a $\mathrm{N}_{2}$-plasma-treated sample.

stitution as well as oxygen functionality (specifically $-\mathrm{O}-\mathrm{C}=\mathrm{O}$ groups). The present study predicts that the combination of various plasma techniques $\left(\mathrm{O}_{2} / \mathrm{N}_{2}\right)$ and thermal activation could produce an ideal electrode for the anode in VRFB.

\section{Conclusion}

When PAN-based GFD-type felts are subjected to $\mathrm{N}_{2}$ plasma treatment, defects are formed on the carbon felt. In addition to the increase in the amount of reactive edge sites, also heteroatom defects involving $\mathrm{N}$-doping are created by the $\mathrm{N}_{2}$ plasma treatment. The surface of the plasma-treated samples was characterized by the presence of pyrrolic and pyridinic nitrogen. The $\mathrm{N}_{2}$-plasma-treated felt showed enhanced electrochemical performance compared to the pristine felt. Since both the pristine as well as the $\mathrm{N}_{2}$-plasma-treated sample had almost the same amount of oxygen functional groups, the superior performance observed for the former one is attributed to the additional defects formed during the plasma treatment. Nevertheless, the cell operated with the $\mathrm{N}_{2}$-plasma-treated sample suffered from capacity fade, which can most likely be attributed to hydrogen evolution at the negative electrode. Therefore, it may be concluded that for the optimum performance of the VRFB, a balance should be found between the amount of various defects such as heteroatom doping, edge sites and functional groups.

\section{Experimental}

\section{Plasma treatment process}

The plasma treatment was carried out on a pristine GFD-type carbon felt, obtained from SGL Carbon (SIGRACELL GFD3 EA), having a thickness of $3 \mathrm{~mm}$, in a radiofrequency (rf) 13.56 MHz plasma setup (Femto, Diener electronic GmbH, Germany) [28]. The power rating of the $\mathrm{rf}$ generator is $300 \mathrm{~W}$ (max. rf power limited to $200 \mathrm{~W}$ ). $5 \times 5 \mathrm{~cm}$ felts were loaded into the plasma chamber which was subsequently evacuated to a pressure below 0.2 mbar before the chamber was filled with about 0.8 mbar of nitrogen. All plasma treatments were carried out for $40 \mathrm{~min}$ at $20 \%$ of the maximum power. In the present work a capacitively coupled parallel plate rf plasma was used. The separation between the plate was $10 \mathrm{~cm}$ and the samples were always placed on the bottom plate without any further connections.

\section{Raman spectroscopy}

Raman measurements were carried out using a HORIBA (model: LabRAM HR Evolution) Raman spectrometer and microscope. An Oxxius $532 \mathrm{~nm}$ laser $(100 \mathrm{~mW})$ and a $50 \times$ optical lens were used to obtain the spectra. The spectra were recorded between $500 \mathrm{~cm}^{-1}$ to $3000 \mathrm{~cm}^{-1}$. The spectra were recorded with an acquisition time of $3 \mathrm{~s}$. To prevent sample damage, the laser power was reduced to $10 \%$.

\section{X-ray photoelectron spectroscopy (XPS)}

XPS measurements were performed using a K-Alpha XPS instrument (Thermo Fisher Scientific, East Grinstead, UK). The data acquisition and processing using the Thermo Advantage software is described elsewhere [29]. All samples were analyzed using a focused (30-400 $\mu \mathrm{m}$ spot size), monochromatic Al K $\alpha \mathrm{X}$-ray source. The K $\alpha$ charge compensation system was employed during the experiment, using electrons of $8 \mathrm{eV}$ energy and low-energy argon ions to prevent any localized charge build-up. The spectra were fitted with one or more Voigt profiles (binding energy (BE) uncertainty: $\pm 0.2 \mathrm{eV}$ ). The analyzer transmission function, Scofield sensitivity factors [29], and effective attenuation lengths (EALs) for photoelectrons were applied for quantification. The EALs were calculated using the standard TPP-2M formalism [30]. All spectra were referenced to the $\mathrm{C} 1 \mathrm{~s}$ peak of hydrocarbon at $285.0 \mathrm{eV}$ binding energy, controlled by means of the well-known photoelectron peaks of metallic $\mathrm{Cu}, \mathrm{Ag}$, and $\mathrm{Au}$.

\section{Scanning electron microscopy (SEM)}

The carbon surface fiber morphology was investigated in a Zeiss Supra 55 SEM with primary electron energies of $5 \mathrm{keV}$ and $15 \mathrm{keV}$ and an in-lens detector. 


\section{Electrochemical measurements}

In this work, commercial carbon felts obtained from SGL Carbon in pristine form and after $\mathrm{N}_{2}$ plasma treatment were used as electrode materials. Cyclic voltammetry (CV) was performed in a three-electrode setup using a Reference 3000 instrument from Gamry with a $\mathrm{Ag} / \mathrm{AgCl}$ reference electrode and a platinum mesh as a counter electrode. A modified configuration developed by Fink et al. was used as the setup for the working electrode (WE) [31]. The configuration was modified so that punched-out disks ( $\varnothing=6 \mathrm{~mm}$ ) of the felts attached to a glassy carbon rod were used as the WE. To achieve a better electrical contact, the punched-out felt was pierced through the middle by $5 \mathrm{~cm}$ long glassy carbon rod with a diameter of $1 \mathrm{~mm}$. The positive half-cell reaction was measured in 0.1 molar vanadyl sulphate (Alfa Aeser) dissolved in 2 molar sulfuric acid (Sigma Aldrich). In order to obtain the $\mathrm{V}^{3+}$ electrolyte for the negative half-cell reaction, both tanks were filled with the same volume of the $\mathrm{V}^{4+}$ electrolyte and then potentiostatically charged at $1.7 \mathrm{~V}$ in a $10 \mathrm{~cm}^{-2}$ flow cell. The reduction to $\mathrm{V}^{3+}$ was determined as complete when the charging current reached less than $10 \mathrm{~mA} \mathrm{~cm}{ }^{-2}$. All the cyclic voltammetry measurements were carried out at a scan rate of $5 \mathrm{mV} \mathrm{s}^{-1}$.

Single-cell measurements were performed using a modified direct methanol fuel cell from ElectroChem, having a pin-type flow field with an active area of $25 \mathrm{~cm}^{2}$. Additionally, a $2 \mathrm{~mm}$ Viton gasket was used as a spacer around the flow fields to achieve uniform compression. A commercial electrolyte from GFE GmbH Germany with $1.6 \mathrm{M}$ vanadium salt $\left(50 / 50 \mathrm{~mol} / \mathrm{mol} \mathrm{V}^{4+} / \mathrm{V}^{3+}\right)$ and an anion exchange membrane, VX 20 from Fumatech was used for most of the single-cell experiments. Galvanostatic cycling was carried out using a singlecell test bench from Scribner (875 Redox Flow Cell Test System) at current densities of 32, 48, and $64 \mathrm{~mA} \mathrm{~cm}^{-2}$. Both electrolyte tanks were filled with $100 \mathrm{~mL}$ of electrolyte and the negative tank was always kept under nitrogen gas flow. Cut-off voltages of $1.8 \mathrm{~V}$ and $0.7 \mathrm{~V}$ were used for the charging and discharging steps, respectively. Between the charging and discharging, the cell was kept at an open-circuit voltage condition for $5 \mathrm{~min}$. Long-term cycling measurements were carried out at a current density of $80 \mathrm{~mA} \mathrm{~cm}^{-2}$ with fresh electrolyte and fresh electrode and activated Nafion 117 membrane. In all the experiments, the electrolyte flow rate was kept at $100 \mathrm{~mL} \mathrm{~min}^{-1}$. The temperature of the cell and electrolyte was maintained at $22{ }^{\circ} \mathrm{C}$ throughout the electrochemical investigations.

\section{Acknowledgements}

Ditty Dixon greatly acknowledge the financial support from SERB, India, under the grant number SB/S2/RJN-162/2017. This work contributes to the research performed at CELEST
(Center for Electrochemical Energy Storage Ulm-Karlsruhe). This work was carried out with the support of the Karlsruhe Nano Micro Facility (KNMF), a Helmholtz Research Infrastructure at the Karlsruhe Institute of Technology (KIT).

\section{ORCID ${ }^{\circledR}$ iDs}

Ditty Dixon - https://orcid.org/0000-0002-6529-6936 Hans-Michael Bruns - https://orcid.org/0000-0002-0462-3948 Helmut Ehrenberg - https://orcid.org/0000-0002-5134-7130

\section{References}

1. SkyllasKazacos, M.; Rychcik, M.; Robins, R. G.; Fane, A. G.; Green, M. A. J. Electrochem. Soc. 1986, 133, 1057-1058. doi:10.1149/1.2108706

2. Tang, A.; Bao, J.; Skyllas-Kazacos, M. J. Power Sources 2011, 196, 10737-10747. doi:10.1016/j.jpowsour.2011.09.003

3. Shah, A. A.; Al-Fetlawi, H.; Walsh, F. C. Electrochim. Acta 2010, 55, 1125-1139. doi:10.1016/j.electacta.2009.10.022

4. Whitehead, A. H.; Harrer, M. J. Power Sources 2013, 230, 271-276. doi:10.1016/j.jpowsour.2012.11.148

5. Wang, L.; Zhang, H.; Cao, G.; Zhang, W.; Zhao, H.; Yang, Y. Electrochim. Acta 2015, 186, 654-663. doi:10.1016/j.electacta.2015.11.007

6. Langner, J.; Bruns, M.; Dixon, D.; Nefedov, A.; Wöll, C.; Scheiba, F.; Ehrenberg, H.; Roth, C.; Melke, J. J. Power Sources 2016, 321 , 210-218. doi:10.1016/j.jpowsour.2016.04.128

7. Dixon, D.; Babu, D. J.; Langner, J.; Bruns, M.; Pfaffmann, L.; Bhaskar, A.; Schneider, J. J.; Scheiba, F.; Ehrenberg, H. J. Power Sources 2016, 332, 240-248. doi:10.1016/j.jpowsour.2016.09.070

8. Agar, E.; Dennison, C. R.; Knehr, K. W.; Kumbur, E. C. J. Power Sources 2013, 225, 89-94. doi:10.1016/j.jpowsour.2012.10.016

9. Derr, I.; Bruns, M.; Langner, J.; Fetyan, A.; Melke, J.; Roth, C. J. Power Sources 2016, 325, 351-359. doi:10.1016/j.jpowsour.2016.06.040

10. Derr, I.; Przyrembel, D.; Schweer, J.; Fetyan, A.; Langner, J.; Melke, J.; Weinelt, M.; Roth, C. Electrochim. Acta 2017, 246, 783-793. doi:10.1016/j.electacta.2017.06.050

11. Estevez, L.; Reed, D.; Nie, Z.; Schwarz, A. M.; Nandasiri, M. I.; Kizewski, J. P.; Wang, W.; Thomsen, E.; Liu, J.; Zhang, J.-G.; Sprenkle, V.; Li, B. ChemSusChem 2016, 9, 1455-1461. doi:10.1002/cssc.201600198

12. Schweiss, R.; Pritzl, A.; Meiser, C. J. Electrochem. Soc. 2016, 163, A2089-A2094. doi:10.1149/2.1281609jes

13. Boukhvalov, D. W.; Katsnelson, M. I. Nano Lett. 2008, 8, 4373-4379. doi:10.1021/nl802234n

14. Banhart, F.; Kotakoski, J.; Krasheninnikov, A. V. ACS Nano 2011, 5 , 26-41. doi:10.1021/nn102598m

15. Wang, S.; Zhao, X.; Cochell, T.; Manthiram, A. J. Phys. Chem. Lett. 2012, 3, 2164-2167. doi:10.1021/jz3008744

16. He, Z.; Shi, L.; Shen, J.; He, Z.; Liu, S. Int. J. Energy Res. 2015, 39, 709-716. doi:10.1002/er.3291

17. Ferrari, A. C. Solid State Commun. 2007, 143, 47-57. doi:10.1016/j.ssc.2007.03.052

18. Pimenta, M. A.; Dresselhaus, G.; Dresselhaus, M. S.; Cançado, L. G.; Jorio, A.; Saito, R. Phys. Chem. Chem. Phys. 2007, 9, 1276-1290. doi:10.1039/b613962k 
19. Ouyang, B.; Zhang, Y.; Wang, Y.; Zhang, Z.; Fan, H. J.; Rawat, R. S. J. Mater. Chem. A 2016, 4, 17801-17808. doi:10.1039/c6ta08155j

20. Babu, D. J.; Bruns, M.; Schneider, R.; Gerthsen, D.; Schneider, J. J. J. Phys. Chem. C 2017, 121, 616-626. doi:10.1021/acs.jpcc.6b11686

21. Kiuchi, H.; Shibuya, R.; Kondo, T.; Nakamura, J.; Niwa, H.; Miyawaki, J.; Kawai, M.; Oshima, M.; Harada, Y. Nanoscale Res. Lett. 2016, 11, 127. doi:10.1186/s11671-016-1344-6

22. Nevidomskyy, A. H.; Csányi, G.; Payne, M. C. Phys. Rev. Lett. 2003, 91, 105502. doi:10.1103/physrevlett.91.105502

23. Rabbow, T. J.; Trampert, M.; Pokorny, P.; Binder, P.; Whitehead, A. H. Electrochim. Acta 2015, 173, 24-30. doi:10.1016/j.electacta.2015.05.058

24. Xu, A.; Shi, L.; Zeng, L.; Zhao, T. S. Electrochim. Acta 2019, 300, 389-395. doi:10.1016/j.electacta.2019.01.109

25. Chen, P.; Fryling, M. A.; McCreery, R. L. Anal. Chem. (Washington, DC, U. S.) 1995, 67, 3115-3122. doi:10.1021/ac00114a004

26. Pourbaix, M. Electrochemical Equilibria in Aqueous Solutions; Pergamon Press: Oxford, United Kingdom, 1966.

27. Nose, M.; Kinumoto, T.; Choo, H.-S.; Miyazaki, K.; Abe, T.; Ogumi, Z. Fuel Cells 2009, 9, 284-290. doi:10.1002/fuce.200800077

28. Babu, D. J.; Yadav, S.; Heinlein, T.; Cherkashinin, G.; Schneider, J. J. J. Phys. Chem. C 2014, 118, 12028-12034. doi:10.1021/jp5027515

29. Parry, K. L.; Shard, A. G.; Short, R. D.; White, R. G.; Whittle, J. D.; Wright, A. Surf. Interface Anal. 2006, 38, 1497-1504. doi:10.1002/sia.2400

30. Tanuma, S.; Powell, C. J.; Penn, D. R. Surf. Interface Anal. 2011, 43, 689-713. doi:10.1002/sia.3522

31. Fink, H.; Friedl, J.; Stimming, U. J. Phys. Chem. C 2016, 120 , 15893-15901. doi:10.1021/acs.jpcc.5b12098

\section{License and Terms}

This is an Open Access article under the terms of the Creative Commons Attribution License (http://creativecommons.org/licenses/by/4.0). Please note that the reuse, redistribution and reproduction in particular requires that the authors and source are credited.

The license is subject to the Beilstein Journal of Nanotechnology terms and conditions:

(https://www.beilstein-journals.org/bjnano)

The definitive version of this article is the electronic one which can be found at: doi:10.3762/bjnano.10.165 